\title{
Bilişsel Radyolarda Beklenti Maksimizasyonu ile Gauss Karışım Modelleri Kestirimi
}

\author{
Fatih Yavuz Ilgin ${ }^{1 *}$ \\ ${ }^{1}$ Erzincan Binali Yyıldırım Üniversitesi, Mühendislik Fakültesi, Elektrik Elektronik Müh. Bölümü, Türkiye (ORCID: 0000-0002-7449-4811)
}

(İlk Geliş Tarihi 23 Nisan 2020 ve 21 Haziran 2020)

(DOI: 10.31590/ejosat.726040)

ATIF/REFERENCE: Ilgın F. Y. (2020). Bilişsel Radyolarda Beklenti Maksimizasyonu Algoritması ile Gauss Karışım Modelleri Kestirimi. Avrupa Bilim ve Teknoloji Dergisi, (19), 588-595.

\section{Öz}

Günümüzde radyo frekans spektrumuna sürekli artan bir talep olduğu bilinmektedir. Bu durumun en büyük sebebi kablosuz haberleşme sistemlerinde iletilen veri boyutlarının sürekli artmasıdır. Bu nedenle Bilişsel Radyo (BR) sistemleri gelecekte yaşanacak spektrum kıtlığı problemlerine çözüm olabilecek potansiyel teknolojilerdir. BR sistemlerinde spektrum algılamanın temelinde algılanacak işaretin olasılık dağılım fonksiyonundan faydalanılmaktadır. Kablosuz haberleşme sistemlerinde spektrum algılama işlemini gerçekleştirecek olan BR kullanıcılarının uzaysal konumuna göre algıladığı işaretlerin olasılık dağılım fonksiyonları değişiklik göstermektedir. Bu çalışmanın amacı beklenti maksimizasyonu algoritması kullanarak farklı BR kullanıcıları tarafından algılanan işaretlerin, ortak Gauss karışım modelinin tahmin edilmesidir. Yapılan çalışmada benzetim sonuçları farklı BR kullanıcılarının uzaysal farklılıklarını içermesi açısından farklı gürültü seviyeleri ve farklı sayıda Bilişsel Radyo kullanıcı sayısına göre gerçekleştirilmiştir. Böylece tahmin edilen Gauss karışım modelleri kestirimi farklı spektrum algılama modellerine temel oluşturmak için kullanılabilir.

\section{Estrimation of Gauss Mixing Models with Expectation Maximum in Cognitive Radios}

\begin{abstract}
Nowadays, it is known that there is a constantly increasing demand for the radio frequency spectrum. The biggest reason for this situation is the constantly increasing data sizes in wireless communication systems. Therefore, Cognitive Radio (BR) systems are potential technologies that can be a solution to future spectrum shortage problems. In the BR systems, the probability distribution function of the signal to be detected is utilized at the basis of spectrum detection. The probability distribution functions of the signals perceived by BR users according to their spatial location, which will perform spectrum detection in wireless communication systems, vary. The purpose of this study is to predict the common Gaussian mix model of signals perceived by different BR users using the expectation maximization algorithm. In the study, simulation results were performed according to different noise levels and different number of cognitive radio users in terms of spatial differences of different BR users. Thus, the estimated Gaussian mix models can be used to predict different spectrum sensing models.
\end{abstract}

Keywords: Cognitive Radio, Expectation Maximization, Spectrum Efficiency, Spectrum Sensing, Optimization.

\footnotetext{
* Sorumlu Yazar: Erzincan Binali Yıldırım Üniversitesi, Mühendislik Fakültesi, Eleektrik Elektronik Müh. Bölümü, Türkiye (ORCID: 0000-00027449-4811) fyilgin@erzincan.edu.tr
} 


\section{Giriş}

Günümüz kablosuz haberleşme sistemlerinde band genişliği gereksinimlerinin, iletilen veri boyutlarındaki artı̧s sebebi ile oldukça fazla olduğu bilinmektedir. Veri boyutlarında yaşanan bu artış miktarı, önümüzdeki yıllarda da hızlı şekilde gerçekleşeceği düşünülmektedir(Kortun vd., 2014). Artan band genişliği ihtiyacı ise daha fazla spektrum talebini de beraberinde getirmektedir. Fakat spektrumun kablosuz haberleşme sistemleri için kıt kaynak durumda olduğu da bilinmektedir(Liang vd., 2008). O halde mevcut radyo frekans spektrumunun verimli kullanılması zorunluluğu kaçınılmaz bir gerçektir(Çiflikli ve Ilgin, 2018). Spektrumun verimli kullanımının önündeki en büyük engel spektrum paylaşımında kullanılan sabit spektrum atama yöntemleridir. Bu yöntemlerde Lisanslı Kullanıcıya(LK) atanan spektrum bölgesi, bu kullanıcı atanan frekansta aktif olmasa bile başka kullanıcıya açılmamakta ve bu frekans bölgesi atıl duruma geçmektedir. Bu problemi önlemek için dinamik spektrum atama yöntemleri kullanılarak boş spektrum bölgeleri belirlenmeli ve lisanssız kullanıııların erişimine açılmalıdır. Lisanssız kullanıcı belirli bir spektrum bölgesini yasal olarak kullanma hakkı olmayan ve sadece bulduğu spektrum boşluklarında haberleşme yapabilen kullanıcılardır. Lisanslı kullanıcı ise spektrum bölgesini yasal olarak kendisine tahsis edilmiş kullanıcıyı temsil etmektedir. Bu nedenle spektrum boşluklarının bulunması veya başka bir tanımla spektrum algılama, spektrum verimliliği açısından oldukça önemlidir.

Spektrum boşluklarının belirlenmesi için literatürde farklı yöntemler önerilmektedir. Bu yöntemlerden Enerji Algılama (EA) tabanlı yöntem, hesaplama maliyeti bakımından en avantajlı yöntem konumdadır(Shi-Qi vd., 2012). Fakat EA yöntemi ile başarılı bir algılama gerçekleştirmek için ortamdaki gürültü seviyesinin bilinmesi gerekmektedir ( $\mathrm{Li}$ ve Lu, 2016). Gürültü seviyesi genellikle bilinen bir değer olmayıp kestirim yöntemleri kullanılarak belirlenmelidir. Dolayısıyla yapılacak kestirim hataları algılama performansını da olumsuz etkilemektedir(Lavanya ve Bhagyaveni, 2019). Ayrıca EA tabanlı algılamanın en büyük dezavantajı gürültü belirsizliği faktörüne karşı olan kırılganlığıdır. Özdeğer tabanlı ve kovaryans tabanlı algılama yöntemleri de spektrum algılama için yaygın olarak kullanılmaktadır (Soltanmohammadi vd., 2013). Bu yöntemlerin en büyük avantaj1 spektrum algılama işlemini kör olarak yapabilmektedirler. Algılama işlemi için alınan işaret örnekleri yeterli olmaktadır(Bao vd., 2012). Fakat bu yöntemler işlem maliyeti bakımından EA yöntemine göre dezavantajlı konumdadırlar. Spektrum algılama için literatürde özellik algılama, eşleştirilmiş filtre gibi farklı yöntemlerde bulunmaktadır(Aparna ve Jayasheela, 2012). Bu yöntemler belirli dezavantajlarından dolayı uygulamada fazla yer bulamamaktadırlar. Özellikler son yıllarda çok kullanıcılı spektrum algılama yöntemleri için çok sayıda çalışma yapılmıştır. Bu çalışmalar içinde gruplama yöntemleri kullanılarak en başarılı algılama için ikincil kullanıcılar arasında işbirliği yapan yöntemler önerilmektedir(Bazerque ve Giannakis, 2010). Çok kullanıcılı BR sistemlerinde en başarılı algılama yapmak için farklı BR kullanıcılarını bir araya getirmektir(Souid vd., 2017). Bazı yöntemlerde ise algılama sınırını belirleyecek eşik değerini, optimizasyon yöntemleri ile en iyi seviyede tutmaktır(Akyildiz vd., 2011).

Veri gruplama yöntemlerinde Gauss karışım modelleri oldukça fazla kullanılmaktadır. Gauss karışım modellerinin kestirimi için literatürde farklı yöntemler önerilmekle beraber, bu yöntemlerin başında Beklenti Maksimizasyonu(BM) algoritması gelmektedir(Mahmoud ve Xia, 2014). BM algoritması kişilerin davranış özelliklerinin sınıflandırılmasından, mühendislik alanında birçok problemin çözümü için kullanılmıştır(Cappé ve Moulines, 2009; Greff vd., 2017). BM algoritması Gauss karışım modelleri için görüntü ve ses uygulamalarında da kullanılmıştır. Bu çalışmalar içinde karışmış ses işaretlerin ayrıştırılması veya gürültüsüzleştirme (denoising) çalı̧̧maları yer almaktadır(Bailey ve Elkan, 1994). Görüntü işaretlerinde ise eksik verilerin tamamlanması veya veri madenciliği uygulamalarında kullanılmaktadır. Aynı zamanda biyomedikal işaretlerin tanımlanma ve sınıflandırılması gibi uygulamalarda da kullanılmaktadır(Garriga vd., 2016).

$\mathrm{Bu}$ çalışmada ise BR sistemleri için işbirlikli algılama modellerinde, beklenti maksimizasyonu yöntemi ile Gauss karışım modelleri kestirimi yapılmaktadır. Böylece tahmin edilen karışım modeli spektrum algılama uygulamalarında kullanılmaktadır. Yapılan çalışmada belirlenen bir algılama modeli üzerinde, BR kullanıcılarının uzaysal farklılıklarını kullanarak BM algoritması ile olasılık dağılım fonksiyonu (Probability Density Function - PDF) kestirimi yapılmaktadır. Önerilen yöntemin performansını değerlendirmek için BR kullanıcıları farklı ortalama ve standart sapmalarda seçilmiştir. Ayrıca BM algoritması için farklı adım boyutlarının hesaplama süreleri de verilmektedir.

\section{Bilişsel Radyo ve Karışım Modelleri için Temel Bilgiler}

BR sistemlerinde karışım modeli için Şekil 1 ile verilen algılama modeli örnek gösterilebilir. Verilen şekilde Birincil Verici İstasyonu (BVİ), kendi iletim frekansı ve kapsama alanı içindeki lisanlı kullanıcılar ile haberleşme sağlamaktadır. BVİ'nin kapsama alanı içinde bulunan Bilişsel Kullanıcıların (BK) görevi ise BVİ'nin aktif/pasif olduğunu belirlemektir. Böylece BVİ pasif olduğunda bu frekans bölgesi BK'ların kendi aralarında haberleşmesi için kullanılmaktadır. Algılama teorisine göre BVİ'nin aktif yada pasif olması ikili hipotez ile belirlenmektedir. İkili hipotez aşă̆ıda verilmektedir(Liang vd., 2008).

$$
\begin{array}{ll}
H_{0}: x_{i}(n)=\eta_{i}(n), & i=1,2, \ldots \ldots \ldots, P \\
H_{1}: x_{i}(n)=s_{i}(n)+\eta_{i}(n), & n=1,2, \ldots \ldots \ldots, N
\end{array}
$$




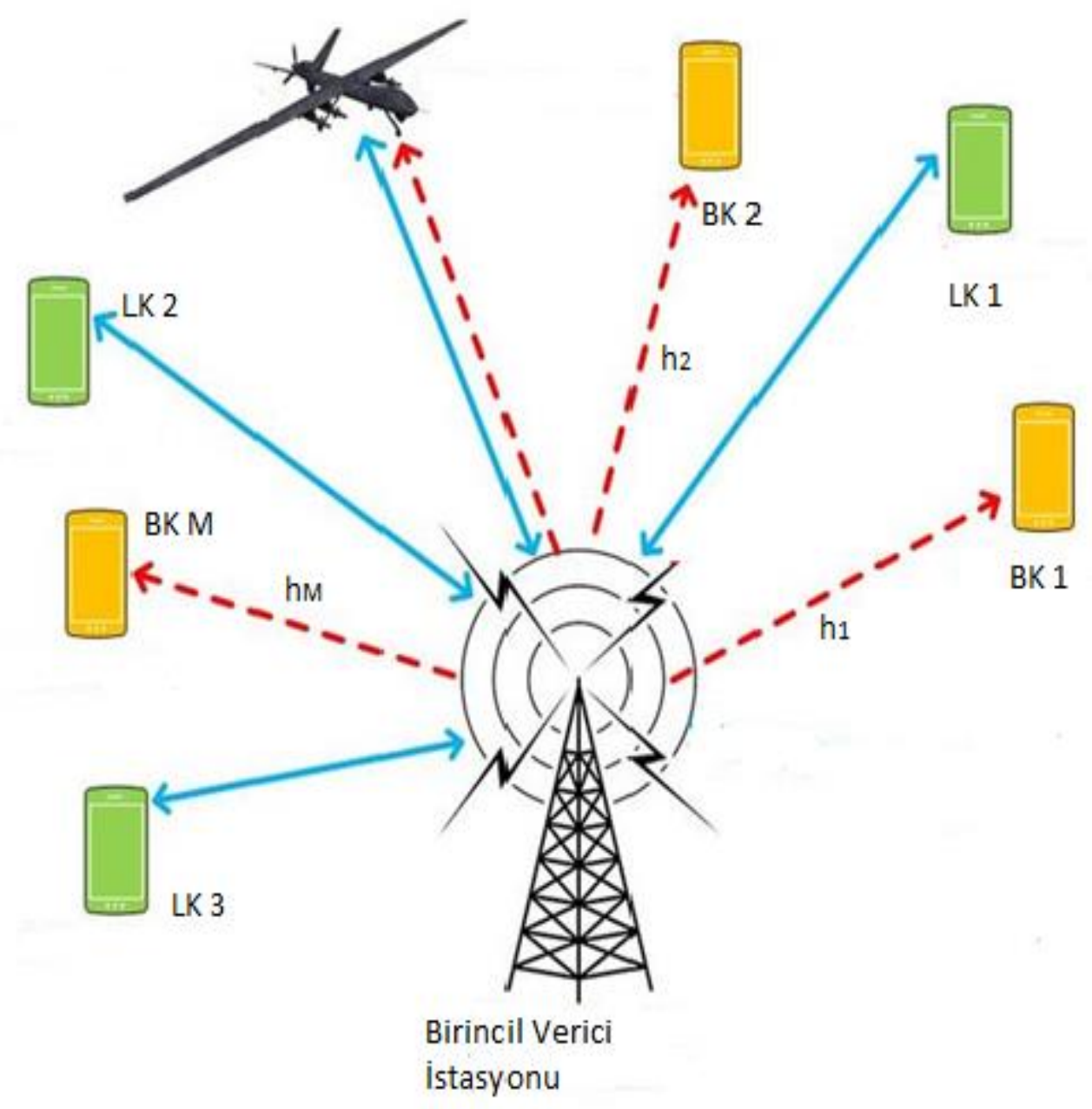

Şekil 1. BR sistemleri için temel algılama modeli

Burada $x_{i}$ ve $s_{i}$ sirasıyla, $\dot{t}$. BR kullanıcısından alınan işaret vektörünü ve BVİ vericisinin işaretini temsil etmektedir. $H_{0}$ ve $H_{1}$ ise BVI'nin pasif ve aktif olduğu durumları belirtmektedir. Ek olarak $P$ algılama modelinde bulunan BR kullanıcı sayısını, $N$ ise bu BR kullanıcılarının algıladığı örnek sysını temsil etmektedir. Enerji Algılama (EA) tabanlı spektrum algılama yönteminde bir test istatistiği ile belirli bir eşik değeri karşılaştırılarak karar verilmektedir. Bu karar mekanizması matematiksel olarak aşağıdaki gibi ifade edilmektedir(Lorincz vd., 2019).

$$
E=\sum_{n=1}^{N}\left|x_{i}(n)\right|^{2} \underset{H_{0}}{\gtrless} \gamma_{E A} \quad H_{0} \text { veya } H_{1}
$$

Burada $\left|x_{i}(n)\right|^{2}$ BR kullanıcıları tarafından alınan işaretin enerjisini temsil etmektedir. $Y_{E A}$ ise EA tabanlı yöntemi için eşik değeri olarak tanımlanmaktadır. Şekil 1'de verilen algılama modelinde BR kullanıcılarının BVI'ye olan uzaklık ve içinde bulunduğu konumundaki gürültü miktarına göre değişmektedir. Şekil 1'de verilen algılama modeli için $P=3$ varsayımı ve rastgele oluşturulmuş kanal katsayıları kullanıldığında, BR kullanıcıları tarafından alınan işaretin enerjisinin olasılık dağılımı aşağıda verilmektedir. 


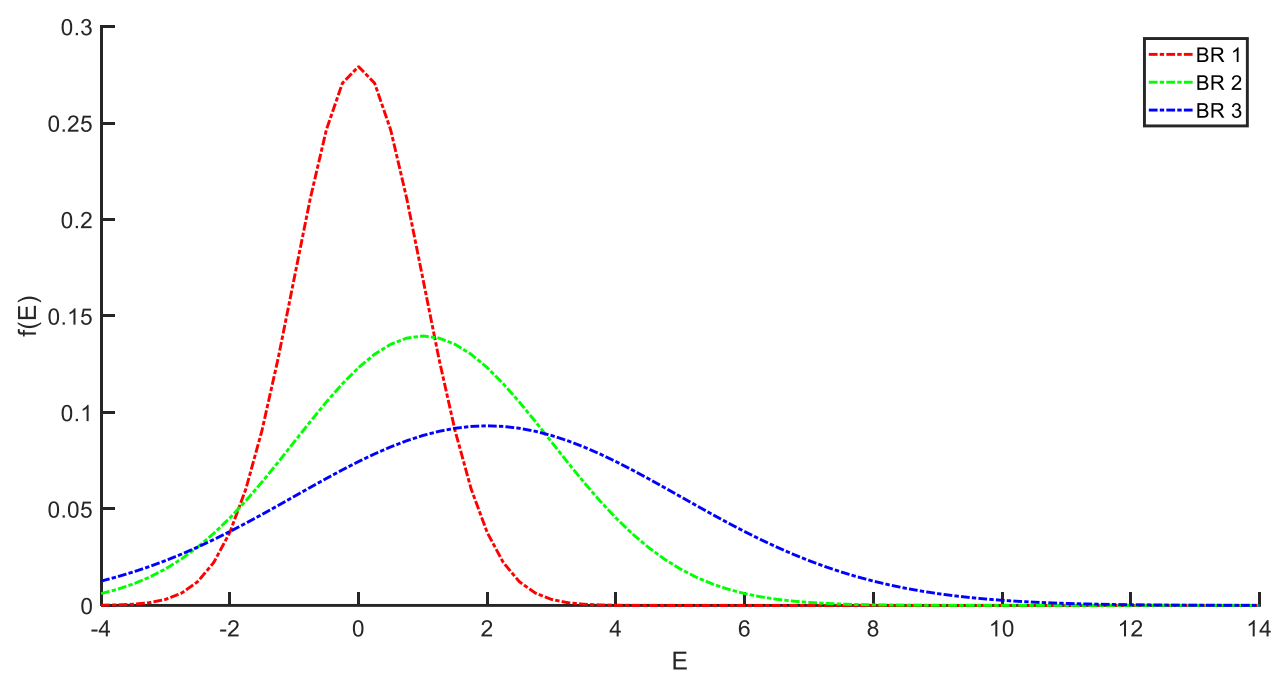

Şekil 2. Rastgele oluşturulmuş BR kullanıcıları için algılanan enerjinin olasılık dağılım fonksiyonları

BR sistemlerinde temel olarak işbirlikli ve işbirliksiz olmak üzere iki tip algılama modeli bulunmaktadır(Bazerque ve Giannakis, 2010). İşbirliksiz algılama modelinde her bir BR kullanıcısı spektrum kararını tek başına kendisi verebilirken, işbirlikli algılamada spektrum kararı sistemde bulunan bütün BR kullanıcılarının ortak kararıdır.

\section{Beklenti Maksimizasyonu ile Gauss Karışım Modelleri Kestirimi}

Gauss Karışım Modeli (GKM) (Gaussian Mixture Model - GMM) Gauss dağılımlı çoklu değişkenlerin modellenmesinde yaygın olarak kullanılan bir yöntemdir. GKM, her biri birer Gauss olasılık dağılımıyla ifade edilen bileşenlerin ağırlıklandırılmış toplamından oluşmaktadır. Gauss karışım modeli ise Eşitlik 4 ile verilmektedir(Rasmussen, 2000).

$$
p(\tilde{x} \mid \Theta)=\sum_{p=1}^{p} h_{p} p\left(\tilde{x} \mid \Theta_{p}\right)
$$

Burada $\tilde{x}$ ve $\theta_{p} \quad$ sirasıyla seçilen öznitelik vektörünü ve modeldeki her bir bileşeni temsil etmektedir. $P$ ise modelde bulunan bileşen sayısını yani BR kullanıcı sayısını göstermektedir. Bu durumda aşağıda verilen eşitlikler yazılabilir(Mahmoud ve Xia, 2014).

$$
p\left(\tilde{x} \mid \Theta_{p}\right) \sim \mathbb{N}\left(\mu_{p}, \Sigma_{p}\right) \text { ve } \sum_{p=1}^{p} h_{p}=1
$$

Gauss karışım modelleri için BM algoritmasını temel olarak iteratif bir optimizasyon yöntemi olarak bilinmektedir. Algoritma, ilk olarak $\Theta_{p}$ tahmininden başlayan ve ardından yakınsama algılanana kadar yinelemeli olarak güncelleştirilir. Her yineleme bir E-adımı ve bir M-adımından oluşmaktadır. E-adımı ve M-adımı sırasıyla beklenti ve maksimizasyon adımları olarak tanımlanmaktadır. Eadımında öncelikle rastgele bir olasılık dağılım fonksiyonu oluşturulmaktadır. Oluşturulan bu fonksiyonun logaritması alınarak logaritmik olasılık dağılım fonksiyonu elde edilmektedir. BM algoritmasında her bir BR kullanıcısından alınana işaretlerin enerjisi $E=\left\{e_{1},{ }^{\cdots} e_{M}\right\}$ olduğunu varsayalım. Bilinmeyen parametreleri $\theta_{p}$ ile tanımladığımız varsayılırsa, BM algoritması ile bulmak istediğimiz kestirimleri $\widetilde{\Theta}_{p}$ ile tanımlanırsa; $\widetilde{\Theta}_{p}$ kestirimi aşağıdaki gibi tanımlanmaktadır(Mahmoud ve Xia, 2014).

$$
\sigma^{B M}=\underbrace{\operatorname{argmax}}_{\theta} P_{0}\left(e_{1,}{ }^{\cdots \cdots}, e_{M}\right)
$$

BM algoritması ile temel amacımız BR kullanıcılarından alınan işaretlere en çok "uyan" maksimum olabilirlikli parametreleri kestirmektir. Pek çok matematiksel modelde, gözlenebilen ölçümler, gözlemlenemeyen değişkenler ile olan ilişkileriyle beraber modellenir. Bu gizli değişkenleri $X=\left\{x_{1}, \cdots x_{M}\right\}$ tanımladığımızı varsayalım. Bu parametreler, gözlemlenemeyen verileri ve bu verilerin ölçümlerle olan korelasyonunu açıklar. Aslında burada temel amaç $p_{0}(Y)$ fonksiyonu maksimize edilmesidir. BM algoritması 
verilen bu ortak olasılık yoğunluk fonksiyonunundan faydalanarak bilinmeyen parametrenin maksimum olabilirlik kestirimini iterasyonlarla bulmaya çalışmaktadır. Algoritmanın $m$. İterasyonunda beklenti bölümü için Eşitlik 7 ile verilen işlemler yapılır.

$$
Q\left(\Theta_{m} \mid \Theta_{m-1}\right)=E_{P_{\Theta_{m-1}}}(X \mid E)\left[\log P_{\Theta}\left(X_{;} \mathrm{E}\right)\right]
$$

Beklenti adımında tüm verinin logolabilirliğinin $\log p \theta(X, Y)_{x}$ gizli değişkenlerin koşullu olasılık yoğunluk fonksiyonuna göre $P_{\Theta_{m i}-1}$ beklentisi hesaplanmaktadır. Bunun için koşullu olasılık fonksiyonu parametrelerin son tahmin değeri kullanılmaktadır. Maksimizasyon bölümü ise matematiksel olarak Eşitlik 8 ile tanımlanmaktadır.

$$
\Theta_{m}=\underbrace{\operatorname{argmax}}_{\theta} Q\left(\Theta_{m} \mid \Theta_{m-1}\right)
$$

Maksimizasyon adımında ise, Beklenti adımında hesaplanan beklenti fonksiyonu $\theta_{m}$ 'e göre maksimize edilmektedir. Beklenti ve maksimizasyon adımları, BM algoritmasının temelini oluşturmaktadır. İteratif olarak beklenti ve maksimizasyon adımlarını tekrar edilerek, belirli bir süre sonunda marjinal olabilirlik fonksiyonunun ekstremum noktalarından birine yakınsamaktadır. Bu yakınsama adımlarının sayısı, başta seçilen rassal değerlere göre değişkenlik göstermektedir. Bu çalışmada kullanılan yöntem aşağıdaki akış diyagramı ile verilmektedir.

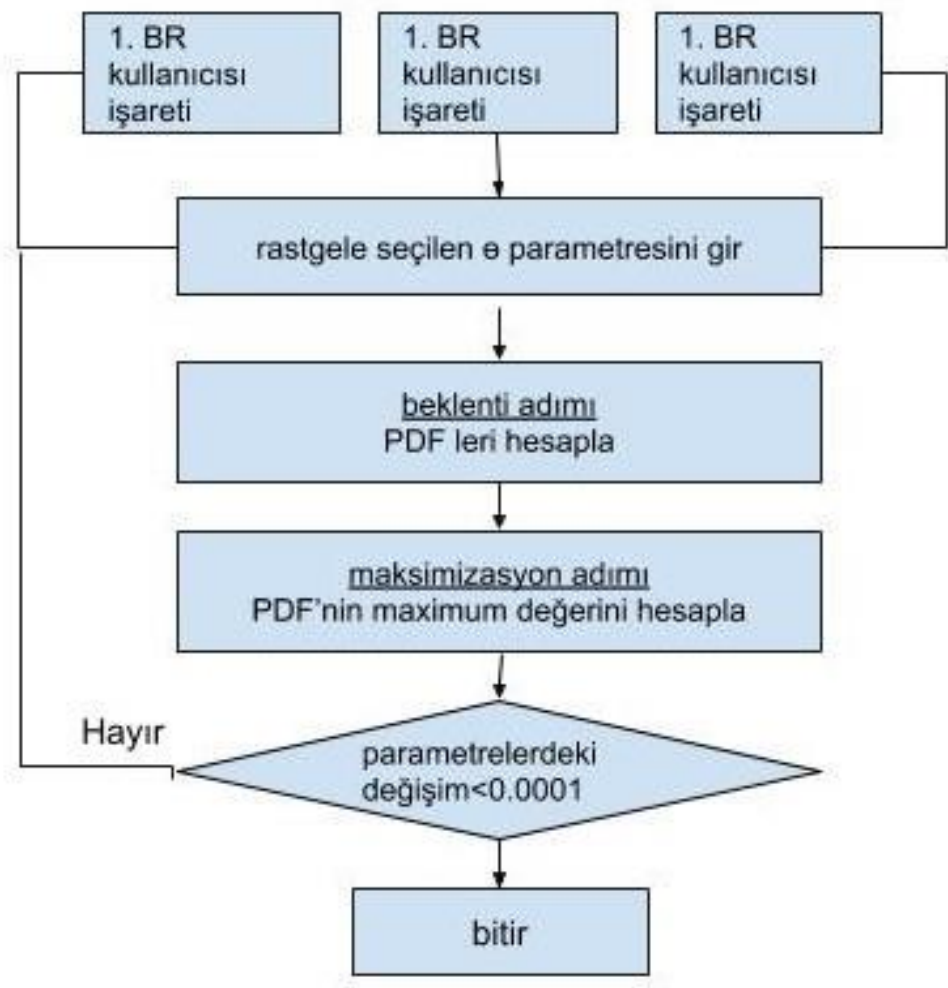

Şekil 3. Önerilen kestirim modeli için akış diyagramı

\section{Deneysel Sonuçlar}

Bu çalışmada deneysel sonuçlar için Şekil 1 ile verilen spektrum algılama modeli kullanılmaktadır. Kanal katsayı vektörü $\left\{h_{1}, \ldots \ldots h_{M}\right\}$ rassal olarak üretilmiştir. Haberleşe kanalı olarak Rayleigh sönümlü kanalı kullanılmıștır. Böylelikle her bir BR kullanıcısının anteni vasıtasıyla algıladığı işaretin enerjisi (E) farklı olasılık dağılımına sahip olmaktadır. Benzetim çalışmaları için 
verilen grafiklerde $\mu_{1}$ ve $\sigma_{1}, 1$. BR kullanıcısı tarafından alınan işaretin enerjisinin ortalamasını ve standart sapmasını belirtmektedir. Ayrıca grafiklerde mavi çizgi ile belirtilen Gauss karışım modelini temsil etmektedir. Gauss karışım modeli teorik olarak Eşiklik 4 ile ifade edilmektedir. Algılama modeline göre sistemde 3 adet BR kullanıcısı olduğunda, her bir kullanıcının algıladıkları işaret enerjilerinin olasılık dağılım fonksiyonları, Gauss karışım modeli ve BM algoritması ile kestirim sonuçları Şekil 3 ile verilmektedir. Şekilden görüldüğü üzere 3 BR kullanıcısı için hem ortalama $(\mu)$ ve standart sapma $(\sigma)$ değerleri verilmektedir. Bu değerler önceden de bahsedildiği gibi rassal olarak üretilmiştir. BM algoritması ile bulunan kestirim sonucuna bakıldığında, 3 farklı BR kullanıcı işaretine yakın olduğu görülmektedir.

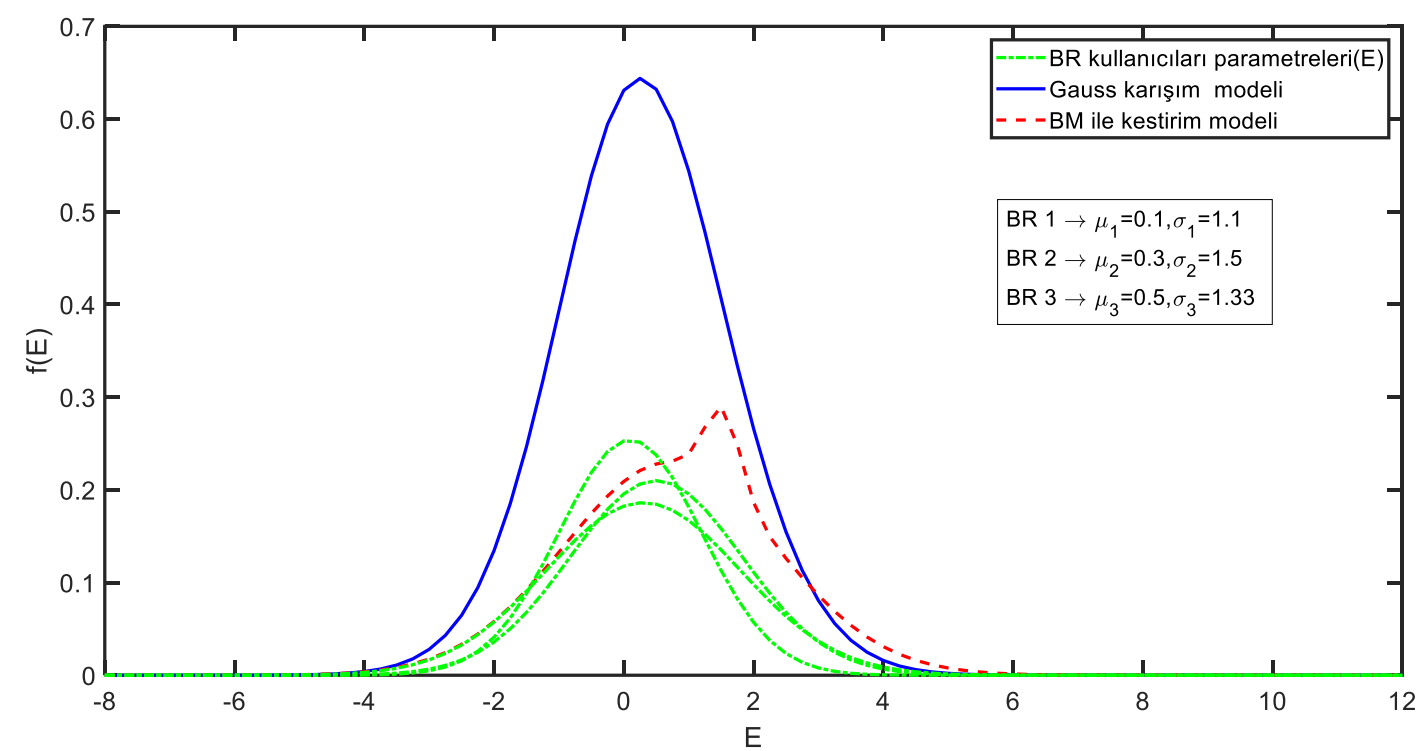

Şekil 4. Rassal üretilmiş $\mu=[0.1,0.3,0.5]$ ve $\sigma=[1,1,1.5,1.33]$ değerleri için BM algoritması kestirim sonucu ve Gauss karışım modeli

Sistemde $\mu=[0.1,0.8,0.9]$ ve $\sigma=[1.91,1.5,1.33]$ sahip veri içeren 3 adet BR kullanıcısı olduğunda kestirim işareti Şekil 5 ile verilmektedir. Burada BM algoritmasının oluşturduğu kestirim işaretinin ortalamasının yaklaşık 1.9 olduğu görülmektedir. Fakat kestirim işaretinin ortalamasının 1 seviyelerinde olması beklenmektedir. Çünkü 3 farklı BR kullanıcısının ortalaması 1 dedir. Bu nedenle BM algoritmasının başarılı bir kestirim yaptığı söylenemez.

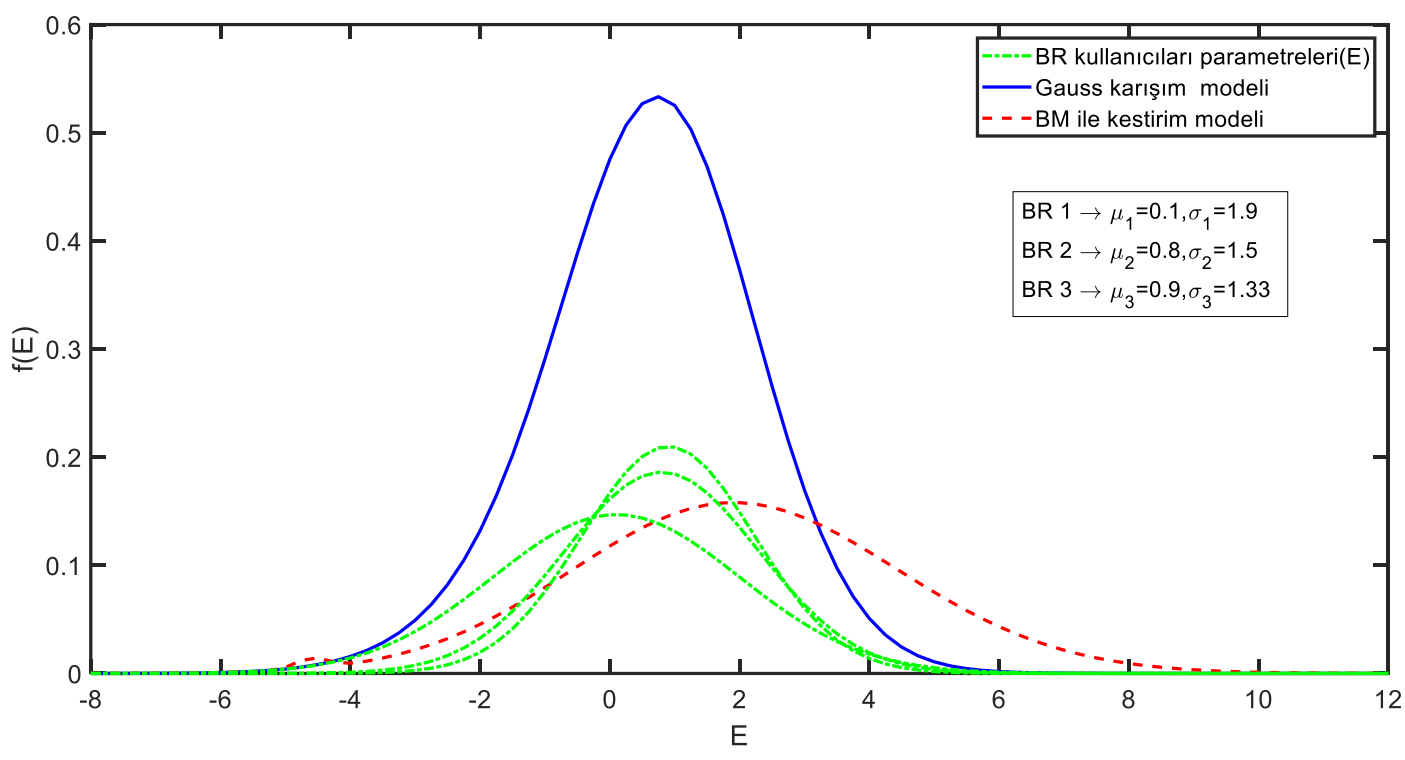

Şekil 5. Rassal üretilmiş $\mu=[0.1,0.8,0.9]$ ve $\sigma=\left[1,91_{v}, 1.5,1.33\right]$ değerleri için BM algoritması kestirim sonucu ve Gauss karışım modeli

Farklı standart sapma ve ortalamalara sahip veri içeren $\mu=[0,1,2]$ ve $\sigma=[1,2,3] 3$ adet BR kullanıcısı olduğunda kestirim işareti Şekil 6 ile verilmektedir. Burada BM algoritmasının oluşturduğu kestirim işaretinin ortalamasının yaklaşık 1.8 olduğu görülmektedir. Görüldüğ̈̈ üzere BM algoritması Gauss karışım modelleri kestiriminde, işaret ortalamaları birbirinden farklı olması hata payını artırmaktadır. Gauss karışım modeline teorisi gereğince, 3 farklı işaretin altında kalan alanların toplamına eşit olduğu görülmektedir. 


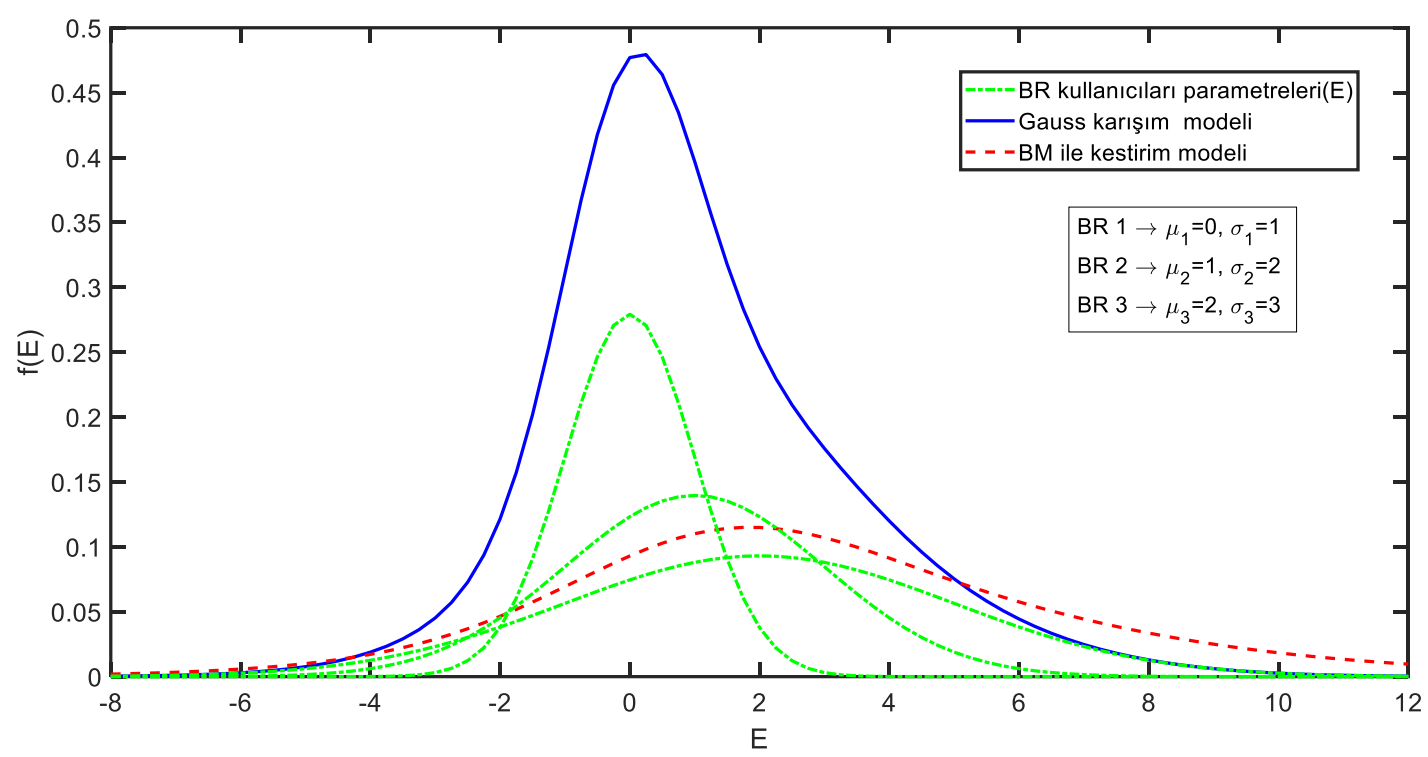

Şekil 6. Rassal üretilmiş $\mu=[0,1,2]$ ve $\sigma=[1,2,3]$ değerleri için BM algoritması kestirim sonucu ve Gauss karışım modeli

Tablo 1 ise farklı BR kullanıcı sayısı ve seçilen adım aralığına göre BM algoritmasının işlem sürelerini göstermektedir. Tablodan görüldüğü üzere BR kullanıcı sayısının azalması işlem süresini de kısaltmaktadır. Aynı zamanda adım aralığının artması işlem süresini de artırdığı söylenebilir. Fakat BM algoritması için verilen akış diyagramından da görüleceği üzere, BM algoritması iteratif bir yöntem olduğundan eski ve yeni parametrelerde değişim olmadığı zaman algoritma işlemi sonlandırmaktadır. Bu sonlandırma parametrelerdeki değişim miktarı ile olabileceği gibi iterasyon sayısı ile de olabilir. Bu çalışmada BM algoritması 25000 iterasyon ve değişim miktarı ile sınırlandırılmıştır. Süre ölçümleri için kullanılan bilgisayar i5 işlemci ve 6 GB ram belleğe sahiptir. Ayrıca kullanılan MATLAB sürümü 2019b' dir.

Tablo 1. BM için adım aralı̆̆ ve işlem süresi

\begin{tabular}{|c|c|c|}
\hline Adım aralı̆̆ı & BR kullanıcı sayısı & Süre(sn) \\
\hline 0.1 & 3 & 1.59 \\
\hline 0.1 & 2 & 1.31 \\
\hline 0.01 & 2 & 0.92 \\
\hline 0.01 & 3 & 0.78 \\
\hline 0.001 & 2 & 1.37 \\
\hline 0.001 & 3 & 1.26 \\
\hline 0.00001 & 2 & 1.22 \\
\hline 0.00001 & & \\
\hline
\end{tabular}

\section{Sonuç}

$\mathrm{Bu}$ çalışmada çok kullanıcılı BR sistemlerinde EA tabanlı algılama modelleri için, algılanan işaretlerin enerjilerinin kestirim çalışmaları yapılmıştır. BR sistemleri için EA tabanlı algılama yöntemlerinde, BR kullanıcıları tarafından alınan işaretlerin enerjisinin olasılık dağılım fonksiyonları, BR kullanıcılarının uzaysal konumuna göre değişmektedir. Çünkü haberleşme işaretinde bulunan gürültü miktarı ve böylece alınan işaretin olasılık dağılım fonksiyonu da değişmektedir. Bu çalışmada algılama modelinde farklı BR kullanıcılarından alınan olasılık dağılım fonksiyonlarının, tek bir fonksiyona indirgenmesi amaçlanmıştır. Bu amaçla farklı BR kullanıcılarının uzaysal farklılıklarını modellemek için rassal işaretler üretilmiş ve bu işaretlerin karışım modelleri BM algoritması ile 
kestirimi yapılmıştır. Benzetim çalışmaları farklı kullanıcı sayısı, farklı adım aralı̆̆ı için yapılmıştır. Böylelikle bu çalışmada elde edilen sonuçlar ile çok kullanıcılı BR sistemlerinde, yeni algılama modelleri kullanılabilir. Kullanılacak bu algılama modelleri ile kullanıcı sayısı azaltımı ve işlem maliyeti bakımından olumlu sonuçlar elde edilebilir.

\section{Kaynakça}

Akyildiz, I. F., Lo, B. F., ve Balakrishnan, R. 2011. Cooperative spectrum sensing in cognitive radio networks: A survey. In Physical Communication. https://doi.org/10.1016/j.phycom.2010.12.003

Bailey, T. L., ve Elkan, C. 1994. Fitting a mixture model by expectation maximization to discover motifs in biopolymers. Proceedings / ... International Conference on Intelligent Systems for Molecular Biology; ISMB. International Conference on Intelligent Systems for Molecular Biology.

Bao, Z., Pan, G., ve Zhou, W. 2012. Tracy-Widom law for the extreme eigenvalues of sample correlation matrices. Electronic Journal of Probability, 17, 1-32. https://doi.org/10.1214/EJP.v17-1962

Bazerque, J. A., ve Giannakis, G. B. 2010. Distributed spectrum sensing for cognitive radio networks by exploiting sparsity. IEEE Transactions on Signal Processing, 58(3), 1847-1862. https://doi.org/10.1109/TSP.2009.2038417

Cappé, O., ve Moulines, E. 2009. On-line expectation-maximization algorithm for latent data models. Journal of the Royal Statistical Society. Series B: Statistical Methodology. https://doi.org/10.1111/j.1467-9868.2009.00698.x

Çiflikli, C., ve Ilgin, F. Y. 2018. Covariance Based Spectrum Sensing with Studentized Extreme Eigenvalue. Technical Gazette, 25(6), $100-106$.

Garriga, J., Palmer, J. R. B., Oltra, A., ve Bartumeus, F. 2016. Expectation-maximization binary clustering for behavioural annotation. PLoS ONE. https://doi.org/10.1371/journal.pone.0151984

Greff, K., Van Steenkiste, S., ve Schmidhuber, J. 2017. Neural expectation maximization. Advances in Neural Information Processing Systems.

Kortun, A., Ratnarajah, T., Sellathurai, M., Liang, Y. C., ve Zeng, Y. 2014. On the eigenvalue-based spectrum sensing and secondary user throughput. IEEE Transactions on Vehicular Technology, 63(3), 1480-1486. https://doi.org/10.1109/TVT.2013.2282344

Lavanya, S., ve Bhagyaveni, M. A. 2019. EVM based rate maximized relay selection for cooperative cognitive radio networks. AEU International Journal of Electronics and Communications, 104, 86-90. https://doi.org/10.1016/j.aeue.2018.12.018

Li, C. M., ve Lu, S. H. 2016. Energy-Based Maximum Likelihood Spectrum Sensing Method for the Cognitive Radio. Wireless Personal Communications, 89(1), 289-302. https://doi.org/10.1007/s11277-016-3266-0

Lorincz, J., Ramljak, I., ve Begušić, D. 2019. A review of the noise uncertainty impact on energy detection with different OFDM system designs. Computer Communications, 148, 185-207. https://doi.org/10.1016/J.COMCOM.2019.09.013

Mahmoud, M., ve Xia, Y. 2014. Expectation Maximization. In Networked Filtering and Fusion in Wireless Sensor Networks. https://doi.org/10.1201/b17667-6

Rasmussen, C. E. 2000. The infinite Gaussian mixture model. Advances in Neural Information Processing Systems.

Aparna, P., ve Jayasheela, M. 2012. Cyclostationary feature detection in cognitive radio using different modulation schemes. International Journal of Computer Applications, 47(21), 975-8887. https://doi.org/10.7763/IJFCC.2013.V2.249

Shi-Qi, L., Bin-Jie, H., ve Xian-Yi, W. 2012. Hierarchical cooperative spectrum sensing based on double thresholds energy detection. Communications Letters, IEEE, 16(7), 1096-1099. https://doi.org/10.1109/LCOMM.2012.050112.120765

Soltanmohammadi, E., Orooji, M., ve Naraghi-Pour, M. 2013. Spectrum sensing over MIMO channels using generalized likelihood ratio tests. IEEE Signal Processing Letters, 20(5), 439-442. https://doi.org/10.1109/LSP.2013.2250499

Souid, I., Ben Chikha, H., Dayoub, I., ve Attia, R. 2017. MIMO relaying networks for cooperative spectrum sensing: False alarm and detection probabilities. Physical Communication, 25, 194-200. https://doi.org/10.1016/j.phycom.2017.07.006

Ying-Chang Liang, Yonghong Zeng, Peh, E. C. Y., ve Anh Tuan Hoang. 2008. Sensing-Throughput Tradeoff for Cognitive Radio Networks. IEEE Transactions on Wireless Communications, 7(4), 1326-1337. https://doi.org/10.1109/TWC.2008.060869 